\title{
Effects of leaf zeatin and zeatin riboside induced by different clipping heights on the regrowth capacity of ryegrass
}

Received: 14 August 2013/ Accepted: 22 November 2013/Published online: 12 December 2013

(C) The Author(s) 2013. This article is published with open access at Springerlink.com

\begin{abstract}
The effect of clipping height on ryegrass regrowth was investigated by examining the roles of several plant hormones. Our study consisted of three treatment conditions: (1) darkness over whole plants, (2) darkness only over stubble leaf sheaths, and (3) light over whole plants. Results showed that under darkness over whole plant, low stubble height resulted in low leaf regrowth biomass. Similar leaf regrowth biomass was observed under conditions of darkness only over stubble leaf sheaths as well as light over whole plants. Each unit weight of stubble at different clipping heights has relatively similar potential of providing stored organic substance for leaf regrowth. Therefore, regrowth index, calculated as newly grown leaf biomass divided by unit stubble weight, was used to evaluate regrowth capacity at different clipping heights under minimal influence of organic substances stored in stubbles. Under light over whole plants and single clipping, low stubble height and high stubble height with root thinning resulted in low leaf biomass and high regrowth index. On the other hand, under light over whole plants and frequent clipping high leaf biomass and regrowth index were observed in high stubble height. In addition, we found that leaf zeatin and zeatin riboside $(\mathrm{Z}+\mathrm{ZR})$ affected ryegrass regrowth and that roots regulated leaf $\mathrm{Z}+\mathrm{ZR}$ concentration. Thus, our results indicate that root-derived cytokinin concentration in leaves influences ryegrass regrowth at different clipping heights.
\end{abstract}

Keywords Ryegrass $\cdot$ Cytokinin $\cdot$ Regrowth $\cdot$ Stubble height

X.-L. Wang $(\bowtie) \cdot$ X.-L. Guo $\cdot$ X.-G. Hou $\cdot$ W. Zhao $\cdot$ G.-W. Xu College of Agronomy, Henan University of Science and

Technology, Luoyang, Henan 471003, China

E-mail: xlwang1975@163.com

Tel.: + 86-379-64282340

Fax: + 86-379-64282340

Z.-Q. Li · X.-L. Wang

State Key Laboratory of Vegetation and Environmental Change, Institute of Botany, Chinese Academy of Sciences,

Beijing 100093, China

\section{Introduction}

Regrowth is one of the most fundamental defense mechanisms of forage grass against herbivorous animals. It is also a very important process for continuous grassland production and hay yield (Guevara et al. 2002; Schiborra et al. 2009). Clipping height is an important factor that influences forage grass regrowth. Zhao et al. (2008) found that high stubble increases the regrowth of Leymus chinensis, whereas low stubble decreases it. Increasing the clipping height from 5 to $8 \mathrm{~cm}$ above the soil surface caused an increase in dry weight per plant of 85.2, 308.3, 393.3, and $51.85 \%$ in Galium aparine L., Galeopsis tetrahit L., Polygonum convolvulus L., and Avena fatua L., respectively (Andreasen et al. 2002). Other studies have also reported that clipping height is an important influencing factor for grass regrowth (Conn and Seefeldt 2009; Gastal et al. 2010; Regmi and Devkota 2009; Zhang et al. 2011). However, the mechanism by which clipping height affects forage grass regrowth remains unknown.

Plant roots are responsible for organic substance storage, water and inorganic nutrient absorption, and growth regulator synthesis (Bano 2010; Shi et al. 2007; Veselova et al. 2005; Yang et al. 2004). Furthermore, in forage grass, roots are important for regrowth. Several studies have shown that concentrations of plant shoot hormones, produced or induced by the roots, influence shoot growth and development. Leaf cytokinin induction by the roots plays a dominant role in adjusting leaf regrowth of ryegrass under frequent clipping (Wang et al. 2012). Vysotskaya et al. (2008) observed an increased abscisic acid concentration in shoots of durum wheat plants grown under nutrient-deficient condition, which is closely associated with its concentration in roots and inhibited growth of shoots. Bacaicoa et al. (2011) reported that root iron absorption induces variation in indole-3-acetic concentration in cucumber shoots, which influences growth and development. Coelho et al. (2013) found that increased mechanical 
impedance in roots of wheat results in reduced shoot growth via a process that is potentially regulated by gibberellins. Thus, the role of root-derived hormones merits strong consideration in studying the effect of clipping height on forage grass regrowth.

Wound healing and new leaf growth of forage grasses in response to clipping require large amounts of energy and materials. Organic substances stored before clipping are important resources for forage grass regrowth (Gan et al. 1999; Hoshino et al. 2009), and several groups have found stored carbohydrates to promote such regrowth (Lee et al. 2009; Turner et al. 2007). Variable clipping height results in variable stubble height and, consequently, varying amounts of aboveground organic storage content. Thus, stubble height is an important factor for forage grass regrowth after clipping. Given this fact, any investigation of the effect of clipping height on forage grass regrowth based on root-derived hormones should carefully minimize or control for the effect of differences organic storage content across stubbles. In the present study, the regrowth index (RI, calculated as newly grown leaf biomass/unit stubble weight) was used to evaluate forage grass regrowth capacity at different clipping heights under minimal influence of stubble organic storage content.

Ryegrass was selected to study forage grass regrowth because it displays rapid growth and is tolerant to grazing. Different cut-root sizes were used to simulate root size variation in regrowth caused by organic substances. Since only the stored carbohydrates of parent plants are involved in leaf regrowth in ryegrass in darkness, an experiment was performed under darkness to determine the pattern of stored carbohydrates involved in leaf regrowth. To investigate the mechanism by which clipping height affects ryegrass regrowth based on root-induced hormones, concentrations of gibberellic acid (GA), abscisic acid (ABA), indole-3-acetic acid (IAA), and zeatin and zeatin riboside $(\mathrm{Z}+\mathrm{ZR})$ in newly grown leaves, concentration of $Z+Z R$ and $A B A$ in the xylem sap, and the amount of water-soluble carbohydrates in roots and stubbles were determined.

\section{Materials and methods}

\section{Experimental design}

The study was conducted at the experimental farm of the College of Agronomy at Henan University of Science and Technology. The grass cultivar, Barwoltra, a variety of Lolium multiflorum from Barenbrug (China), was used in the study. Ryegrass seeds were planted in plastic pots $(20 \mathrm{~cm}$ in diameter, $25 \mathrm{~cm}$ in height, and 13.51 in volume) filled with $5.5 \mathrm{~kg}$ of soil (with $13.5 \mathrm{~g} / \mathrm{kg}$ carbon content), and then grown in a greenhouse for 2 weeks at 19-25 ${ }^{\circ} \mathrm{C}$. Photon flux density during the day varied from 210 to $1,280 \mu \mathrm{mol} \mathrm{m} \mathrm{m}^{-2} \mathrm{~s}^{-1}$ in the greenhouse. Seedlings were transplanted to 200 plastic pots, with six seedlings in each pot, and grown for 2 weeks. Subsequently, 63 pots with uniformly grown and strong seedlings were selected for the study.

Selected seedlings were grown for 6 weeks until the jointing stage. Figure 1 shows a schematic diagram illustrating the ryegrass growth stages. Of the 63 pots, six were taken to the laboratory. Three pots were used for measurements of pre-clipping biomass of roots, stubbles, soluble carbohydrate concentration in roots and stubbles, IAA, GA, ABA, and Z + ZR concentration in newly grown leaves, and $Z+Z R$ and $A B A$ concentration in the xylem sap. The other three pots were clipped transversely through the middle into two factions using a thin-back knife in such a way that the ryegrass roots were also transversely clipped into halves. Then, the lower parts of the pot were discarded, and the upper parts of the pots were used to determine root biomass.

The seedlings in the remaining 57 pots were clipped to stubble heights of 1 or $5 \mathrm{~cm}$. Preliminary experiments revealed that ryegrass displayed good regrowth capacity until the jointing stage, so this period was selected for clipping. Some seedling roots in the 57 pots were thinned in half. For root thinning, the pots were cut transversely through the middle using a thin-back knife so that the ryegrass roots were also transversely clipped into halves.

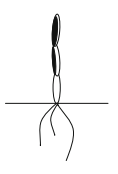

(1)

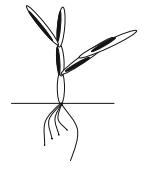

(2)

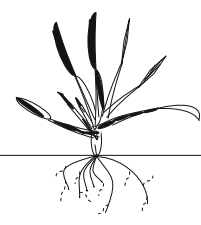

(3)

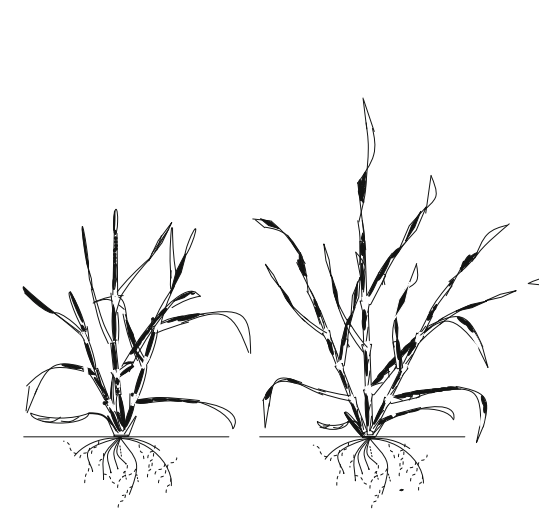

(4)
(5)

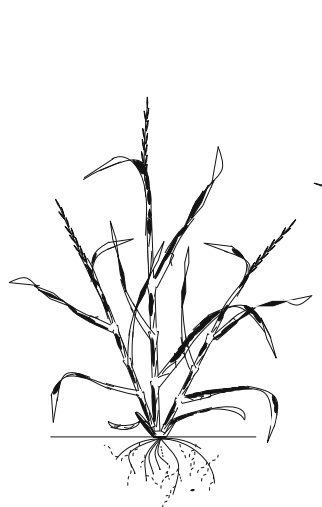

(6)

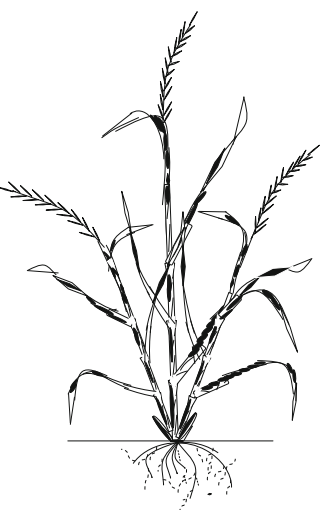

(7)

Fig. 1 A schematic diagram for ryegrass growth stages. 1 Seedling emergence, 2 seedling stage, 3 tillering stage, 4 jointing stage, 5 booting stage, 6 heeding stage, 7 mature stage 


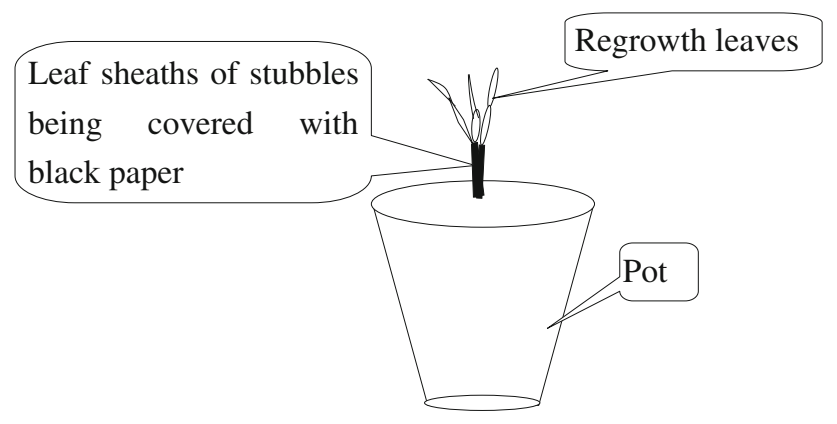

Fig. 2 A schematic diagram for experiment design of Exp-2

The upper and lower halves of roots were kept in place by transparent adhesive tape. During thinning, the pots were kept stable to avoid soil disturbance. In addition, whole plants or only stubble leaf sheaths of some seedlings of the 57 pots were placed in complete darkness according to their experimental conditions.

Eighteen pots were used for darkness in whole plants (Exp-1). A black pot $(23 \mathrm{~cm}$ in diameter and $30 \mathrm{~cm}$ in height) was covered with ryegrass to ensure complete darkness for whole plants. The aim of Exp-1 was to demonstrate the pattern of stored carbohydrates involved in leaf regrowth. Exp-1 had three treatments composed of six pots each: (1) $5-\mathrm{cm}$ stubble height without thinned roots (B5), (2) 1-cm stubble height without thinned roots (B1), and (3) $5-\mathrm{cm}$ stubble height with thinned roots (BD5). The six pots in each treatment group were further divided into two subgroups with three replicate pots each. The pots in each treatment group were clipped to stubbles of $1 \mathrm{~cm}$ (B1) or $5 \mathrm{~cm}$ (B5 and BD5) every 6 days. This procedure was performed three times. After the third clipping procedure, almost no new leaf growth was observed in the samples in Exp1. Six days after each clipping, one subgroup from each treatment group in Exp-1 was taken to the laboratory to determine biomass of regrowth leaves, stubbles and roots, and soluble carbohydrate concentration in roots.

Twelve pots were used to examine the contribution of stored organic substances in stubbles to leaf regrowth (Exp-2). Leaf sheaths of stubbles were covered with black paper to ensure complete darkness over leaf sheaths only (as shown in Fig. 2) and selective utilization of organic substances stored in stubbles for leaf regrowth. Exp-2 consisted of four treatments, each with three pots: (1) darkness over stubble leaf sheaths, $5 \mathrm{~cm}$ stubble height (S5); (2) light over the whole plant, 5-cm stubble height (M5); (3) darkness over stubble leaf sheaths, 1-cm stubble height (S1); (4) light over the whole plant, 1-cm stubble height (M1). The three replicate pots in each treatment condition were clipped to stubble heights of $1 \mathrm{~cm}$ (S1 and M1) or $5 \mathrm{~cm}$ (S5 and M5) every 6 days, and the biomass of the regrowth leaf was measured immediately after clipping. This was done four times.

Twenty-seven pots were used for light over whole plants (Exp-3). Exp-3 consisted of three treatments with a total of nine pots: (1) 5 -cm stubble height without thinned roots (L5); (2) 1-cm stubble height without thinned roots (L1); and (3) $5-\mathrm{cm}$ stubble height with thinned roots (LD5). As in Exp-1, the nine pots in each treatment group were further divided three subgroups with three replicate pots each. All samples in each treatment group were clipped to stubbles of $1 \mathrm{~cm}(\mathrm{~L} 1)$ or $5 \mathrm{~cm}$ (L5 and LD5) every 6 days. This procedure was done four times. Six days after each clipping, one subgroup from each treatment group in Exp-3 was taken to the laboratory to determine the biomass of the regrowth leaves, stubbles, and roots, soluble carbohydrate concentration in stubbles and roots, and concentrations of IAA, GA, ABA, and $Z+Z R$ in newly grown leaves, and $Z+Z R$ and $A B A$ in xylem sap. In summary, the study was composed of three experiments including darkness over whole plants (Exp-1), darkness over leaf sheaths of stubbles (Exp-2), and light over whole plants (Exp-3). A schematic diagram in Fig. 3 clearly displays the experimental design.

\section{Biomass and soluble carbohydrates}

The roots of the seedlings were separated from soil in the pots by washing. Six days after each clipping, leaves that had grown above the stubbles were referred to as regrowth leaves. Fresh root, stubble, and leaf samples were dried in a forced-air oven at $65^{\circ} \mathrm{C}$ for $60 \mathrm{~h}$ to determine biomass. Anthrone colorimetry was used to measure the content of water-soluble carbohydrates in the roots and stubbles (Zou 1995). Samples were taken to measure water-soluble carbohydrates at approximately 6:00 p.m.

Relative growth index (RI) was used to evaluate leaf regrowth at different stubble heights with minimal influence of organic substance from stubbles in Exp-3. RI was determined using the following formulae (1):

$\mathrm{RI}=\frac{\mathrm{LB}_{n+6}}{\mathrm{SB}_{n}} \times 100 \%$

where $\mathrm{RI}$ is the relative regrowth index (\%), and $\mathrm{LB}_{n+6}$ is the newly grown leaf biomass 6 days after each clipping $(\mathrm{g}) ; \mathrm{SB}_{n}$ is the stubble biomass (g) measured immediately after each clipping; and $n$ is clipping time with values of 1,2 , or 3 .

Xylem sap extraction was performed in all treatments in Exp-3. Stem wounds were covered with approximately $0.2 \mathrm{~g}$ of absorbent cotton immediately after clipping, which was tightly wrapped with plastic sheeting to prevent evaporation. After $12 \mathrm{~h}$, the cotton was weighed again. Increase in weight was divided by $1 \mathrm{~g} /$ $\mathrm{cm}^{3}$ to obtain the sap volume. The cotton was placed and then compacted in the bottom of a $10-\mathrm{ml}$ syringe with a piston. Subsequently, $1 \mathrm{ml}$ of $80 \%$ methanol containing $1 \mathrm{mmol} / 1$ di-tert-butyl-4-methylphenol was injected into the syringe, and droplets from the syringe were collected using a 5-ml centrifuge tube. After 


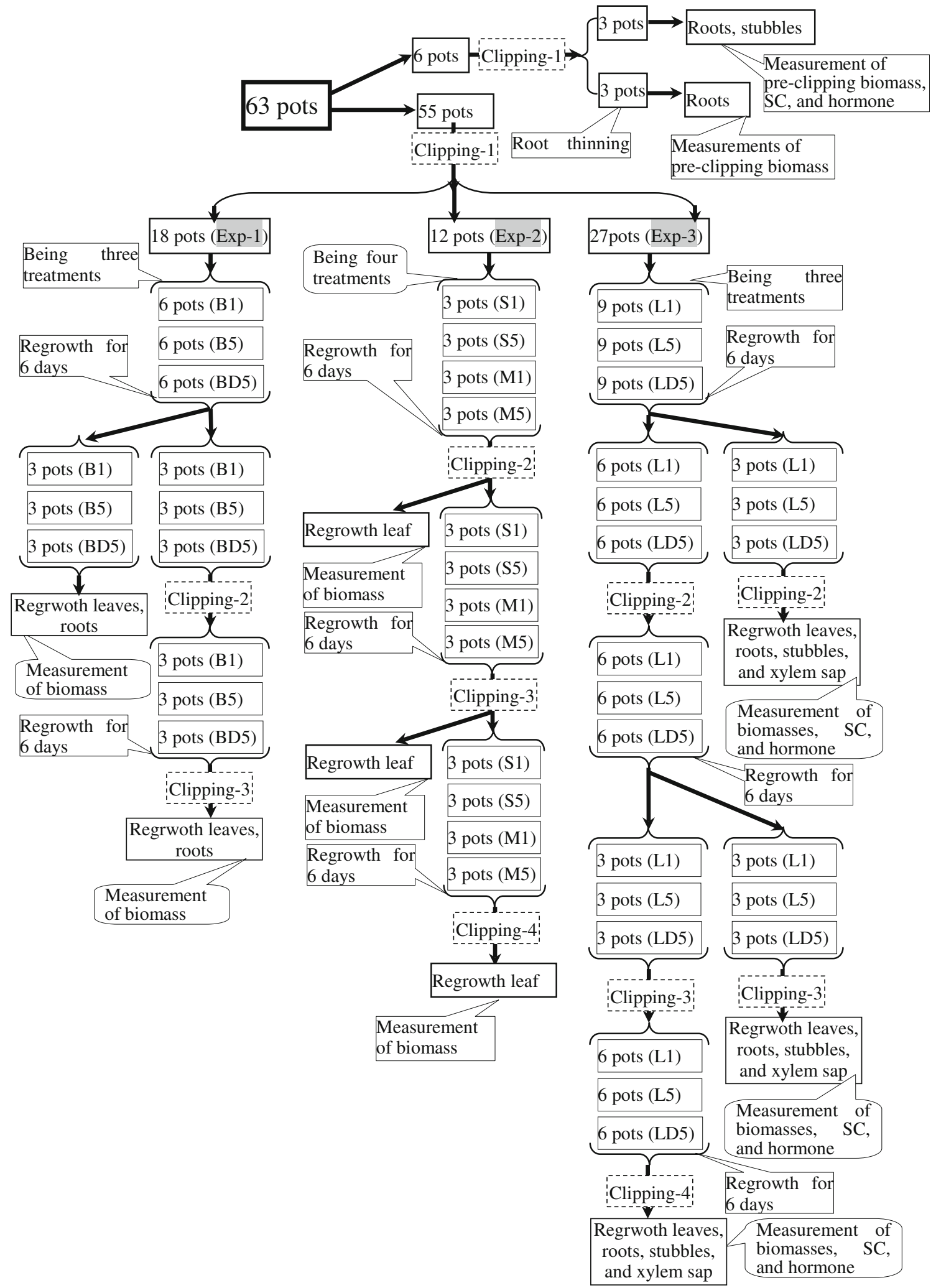

Fig. 3 A schematic diagram for the experimental design. SC soluble carbohydrate, Clipping-1, Clipping-2, Clipping-3, and Clipping-4 the first, second, third, and fourth clippings, respectively, $B 1, B 5, B D 5$ the three treatments of Exp-1, S1, S5, M1, M5 the four treatments of Exp-2, L1, L5, LD5 the three treatments of Exp-3 
approximately $15 \mathrm{~s}$ of natural dripping, the cotton was further compressed using the piston. The remaining xylem sap in the cotton was extracted thrice using the method described above, and the sap from each sample was pooled in a $5-\mathrm{ml}$ centrifuge tube. The extracts were used to measure concentrations of plant hormones in the xylem sap.

\section{Hormones}

After the xylem sap was extracted, it was immediately injected into a solid-phase extraction octadecyl carbon chain C-18 column (Waters Corporation, USA), blowdried with nitrogen, and then stored at $-80{ }^{\circ} \mathrm{C}$ for future measurement of hormone concentrations. Fresh leaf samples $(1-3 \mathrm{~g})$ were frozen in liquid nitrogen for $30 \mathrm{~min}$ and stored at $-80{ }^{\circ} \mathrm{C}$ for the same purpose. Each frozen leaf sample was cut into pieces, and approximately $0.7 \mathrm{~g}$ was weighed and then mixed with $80 \%$ methanol containing $1 \mathrm{mmol} / 1$ di-tert-butyl-4-methylphenol. The mixture was ground into a homogenate in a water bath and then extracted at $4{ }^{\circ} \mathrm{C}$ for $4 \mathrm{~h}$. The samples were centrifuged at 7,000 rpm for $15 \mathrm{~min}$ and precipitated, and the supernatant was subsequently collected. The precipitate was extracted with $80 \%$ methanol for $1 \mathrm{~h}$, and the supernatant was collected again. The supernatants were pooled, injected into a solid-phase extraction C-18 column, and blow-dried with nitrogen. The residues of leaf and xylem sap extract samples were dissolved in $0.01 \mathrm{~mol} / 1$ phosphate buffer solution ( $\mathrm{pH}$ 7.4). The concentrations of IAA, GA $\left(\mathrm{GA}_{1}\right), \mathrm{ABA}$, and $\mathrm{Z}+\mathrm{ZR}$ were determined using an enzyme-linked immunosorbent assay (ELISA) following previously described methods (Teng et al. 2006; Zhang et al. 2009; Zhu et al. 2005). Anti-GA 3 antibody was used for measuring $\mathrm{GA}_{1}$ content by ELISA ( $\mathrm{He} 1993$; Yang et al. 2001).

Mouse monoclonal antigens and antibodies against IAA, GA, ABA, and $\mathrm{Z}+\mathrm{ZR}$, as well as the IgGhorseradish peroxidase used in ELISA, were produced at the Phytohormones Research Institute of China Agricultural University. IAA, GA, ABA, and Z + ZR were studied using the hormone test kit produced by this institute, as described in previous plant hormonal studies (Teng et al. 2006; Zhu et al. 2005; Zhang et al. 2009; Yang et al. 2001). ELISA was performed in a 96-well microtitration plate. Each well was coated with $100 \mu \mathrm{l}$ coating buffer $\left(1.5 \mathrm{~g} / 1 \mathrm{Na}_{2} \mathrm{CO}_{3}, 2.93 \mathrm{~g} / 1 \mathrm{NaHCO}_{3}\right.$, and $0.02 \mathrm{~g} / 1 \mathrm{NaN}_{3}, \mathrm{pH}$ 9.6) with $0.25 \mu \mathrm{g} / \mathrm{ml}$ hormone antigens. The coated plates were incubated at $37^{\circ} \mathrm{C}$ for $4 \mathrm{~h}$. For determination of GA, ABA, and $\mathrm{Z}+\mathrm{ZR}$ concentrations, the plates were incubated at $4{ }^{\circ} \mathrm{C}$. For IAA measurement, the plates were incubated overnight at $4{ }^{\circ} \mathrm{C}$ and then kept at room temperature for $30-40 \mathrm{~min}$. After washing four times with PBS + Tween $20[0.1 \%$ $(\mathrm{v} / \mathrm{v})]$ buffer $(\mathrm{pH} 7.4)$, each well was filled with $50 \mu \mathrm{l}$ of either ryegrass sample extract or IAA, GA, ABA, and $\mathrm{Z}+\mathrm{ZR}$ standards $(0-2,000 \mathrm{ng} / \mathrm{ml}$ dilution range), and $50 \mu \mathrm{l}$ of $20 \mu \mathrm{g} / \mathrm{ml}$ antibodies against IAA, GA, ABA, and $\mathrm{Z}+\mathrm{ZR}$.

The plates were incubated for $3 \mathrm{~h}$ at $28{ }^{\circ} \mathrm{C}$ for GA, $\mathrm{ABA}$, and $\mathrm{Z}+\mathrm{ZR}$, and overnight at $4{ }^{\circ} \mathrm{C}$ for IAA, and then washed four times with PBS + Tween $20[0.1 \%$ $(\mathrm{v} / \mathrm{v})]$ buffer ( $\mathrm{pH}$ 7.4). IgG-horseradish peroxidase substrate $(100 \mu \mathrm{l}$ of $1.25 \mu \mathrm{g} / \mathrm{ml})$ was added to each well, and plates were then incubated for $1 \mathrm{~h}$ at $30^{\circ} \mathrm{C}$. Plates were rinsed five times with PBS + Tween 20 buffer, and then $100 \mu \mathrm{l}$ color-appearing solution containing $1.5 \mathrm{mg} \mathrm{ml}^{-1}$ o-phenylenediamine and $0.008 \%(\mathrm{v} / \mathrm{v}) \mathrm{H}_{2} \mathrm{O}_{2}$ were added to each well. When 2,000 and $0 \mathrm{ng} / \mathrm{ml}$ of the standard showed pale and deep colors in the wells, respectively, the reaction was stopped by adding $50 \mu$ of $6 \mathrm{~N} \mathrm{H}_{2} \mathrm{SO}_{4}$ per well. Color development in each well was detected using an ELISA Reader (Model DG-5023, Huadong Electron Tube Factory, Nanjing, China) at an optical density of $A_{490}$. The concentrations of IAA, GA, $\mathrm{ABA}$, and $\mathrm{Z}+\mathrm{ZR}$ in the leaves and xylem sap were calculated according to the method previously described by Weiler et al. (1981).

The amounts of IAA, GA, ABA, and Z + ZR in the xylem sap were expressed as the products of their respective concentrations in the xylem sap and the volume of the xylem sap. The delivery rates of IAA, $\mathrm{GA}, \mathrm{ABA}$, and $\mathrm{Z}+\mathrm{ZR}$ from the roots to the leaves were expressed as the amounts of IAA, GA, ABA, and $Z+Z R$ in the xylem sap per hour. The percentage recoveries of IAA, GA, ABA, and $Z+Z R$, determined by adding known quantities of the standard hormone to a split extract, were 79.2, 78.6, 80.2, and $83.0 \%$, respectively, indicating absence of nonspecific inhibitors in the extracts. The specificity and other possible nonspecific immunoreactive interference of monoclonal antibodies we used have previously been examined by Wu et al. (1988), Zhang et al. (1991), and $\mathrm{He}$ (1993).

Before the extraction of xylem sap, absorbent cotton was soaked in methanol and air-dried three times in order to reduce contamination for $\mathrm{ABA}$ and $\mathrm{Z}+\mathrm{ZR}$ measurements. Comparison of ABA and $Z+Z R$ concentrations in xylem sap collected by absorbent cotton and by vacuum-extracted revealed no significant difference $(p<0.05)$. Thus, use of the absorbent cotton had little effect on ABA and Z + ZR measurements. In the vacuum-extraction method, a silicon tube was tightly attached to the cut portion of clipped ryegrass, then squeezed to vent air and tied with string at the other end. Twelve hours later, the solution in the silicon tube was collected.

Abbreviations used throughout the text are listed in Table 1. Values in the graphs represent averages and were analyzed with SAS (version 6.12). The least significant difference test was used to perform multiple comparisons among treatments at $p=0.05$. 
Table 1 The abbreviations and symbols used in the text

\begin{tabular}{ll}
\hline Symbol & Definition \\
\hline GA & Gibberellic acid \\
IAA & Indole-3-acetic acid \\
Z + ZR & Zeatin and zeatin riboside \\
ABA & Abscisic acid \\
Exp-1 & Experiment of darkness over whole plants \\
Exp-2 & Experiment of darkness only over stubble leaf sheaths \\
Exp-3 & Experiment of light over whole plants \\
B1 & Treatment of 1-cm stubble height without thinned roots in Exp-1 \\
B5 & Treatment of 5-cm stubble height without thinned roots in Exp-1 \\
BD5 & Treatment of 5-cm stubble height with thinned roots in Exp-1 \\
S1 & Treatment of darkness over stubble leaf sheaths and 1 cm stubble height in Exp-2 \\
S5 & Treatment of darkness over stubble leaf sheaths and 5 cm stubble height in Exp-2 \\
M1 & Treatment of light over the whole plant and 1-cm stubble height in Exp-2 \\
M5 & Treatment of light over the whole plant and 5-cm stubble height in Exp-2 \\
L1 & Treatment of 1-cm stubble height without thinned roots in Exp-3 \\
L5 & Treatment of 5-cm stubble height without thinned roots in Exp-3 \\
LD5 & Treatment of 5-cm stubble height with thinned roots in Exp-3 \\
RI & Regrowth index \\
LB & The newly grown leaf biomass 6 days after each clipping \\
SB ${ }_{n}$ & The stubble biomass measured immediately after each clipping \\
ELISA & Enzyme-linked immunosorbent assay \\
\hline
\end{tabular}
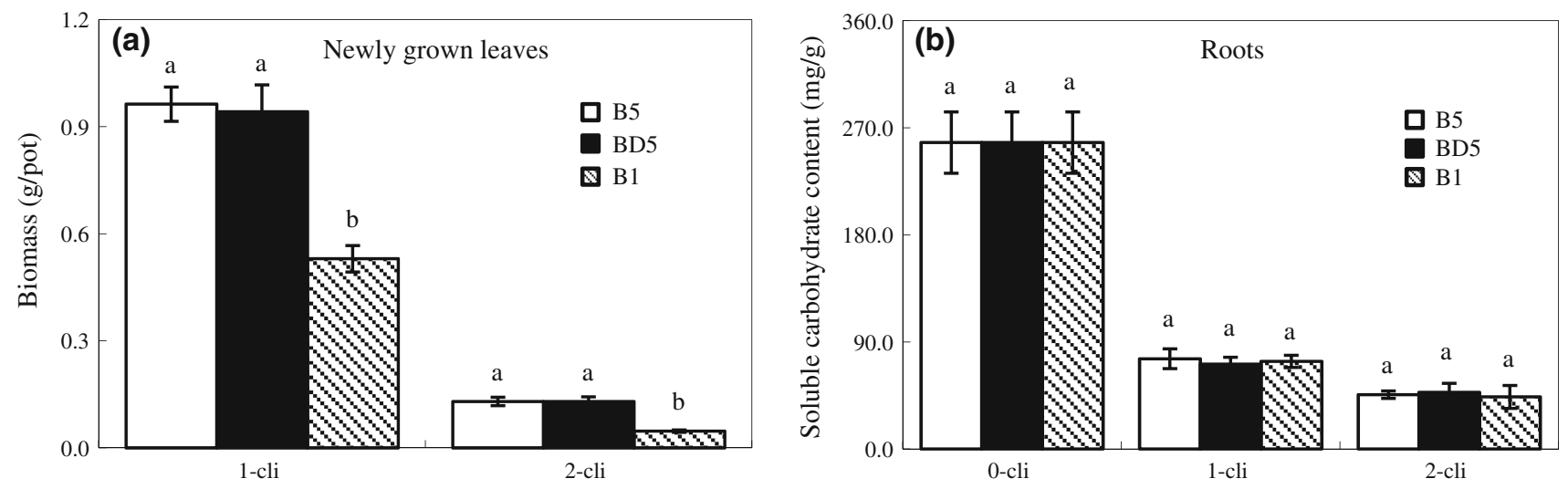

Fig. 4 Newly grown leaf biomass (a) and soluble carbohydrate concentration (b) in the roots in the Exp-1. Values are mean \pm standard error $(n=3)$. Different letters correspond to significant differences at $p \leq 0.05$. " 0 -cli", " 1 -cli", and " 2 -cli" stand for pre-clipping and day 6 after the first and second clippings, respectively

\section{Results}

\section{Exp-1 and Exp-2}

In Exp-1, no significant differences in the biomass of regrowth leaves were found between $\mathrm{B} 5$ and $\mathrm{BD} 5$ groups 6 days after each clipping, and the biomass was significantly higher in these treatment groups than in B1 (Fig. 4a). No significant differences in the soluble carbohydrate concentration of roots were found among B5, BD5, and B1 6 days after each clipping (Fig. 4b). In Exp-2, no significant difference was found in the biomass of regrowth leaves between S1 and M1, and S5 and M5 6 days after each clipping (Fig. 5).

\section{Exp-3}

\section{Biomass}

The biomass of regrowth leaves in all the treatment groups and roots and stubbles in LD5 and L1 decreased from 6 days after the first clipping to 6 days after the third clipping (Fig. 6a-c). Six days after each clipping, regrowth leaf biomass was significantly higher in L5 than in LD5, and the lowest in L1. Root biomass was significantly lower in L1 than in L5, and stubble biomass was significantly lower in LD5 than in L5. These results indicate that low stubble height leads to reduced biomass of regrowth leaves and roots, while high stubble height with root thinning causes decrease in stubble 


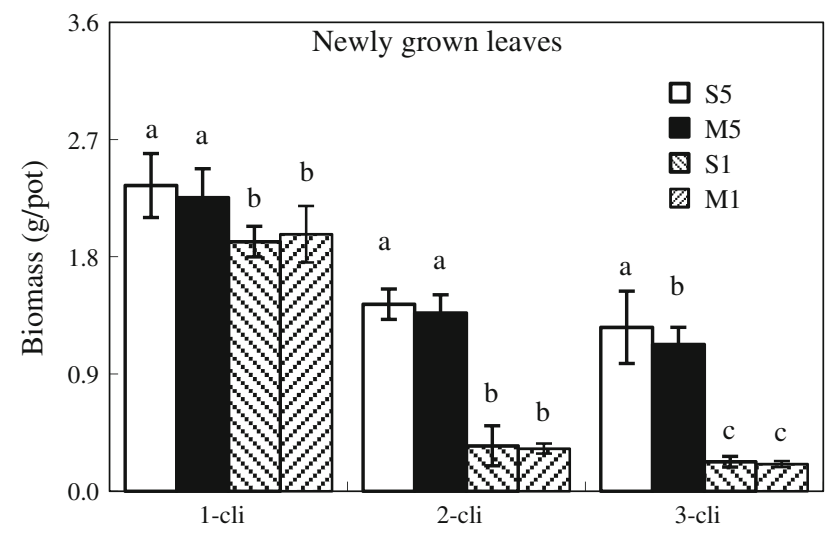

Fig. 5 Newly grown leaf biomass in the Exp-3. Values are mean \pm standard error $(n=3)$. Different letters correspond to significant differences at $p \leq 0.05$. "1-cli", "2-cli", and "3-cli" stand for day 6 after the first, second, and third clippings, respectively

biomass. The root biomass of LD5 increased by $109.0 \%$ from pre-clipping to 6 days after the first clipping and decreased gradually by only $14.5 \%$ from the first clipping to 6 days after the third clipping.
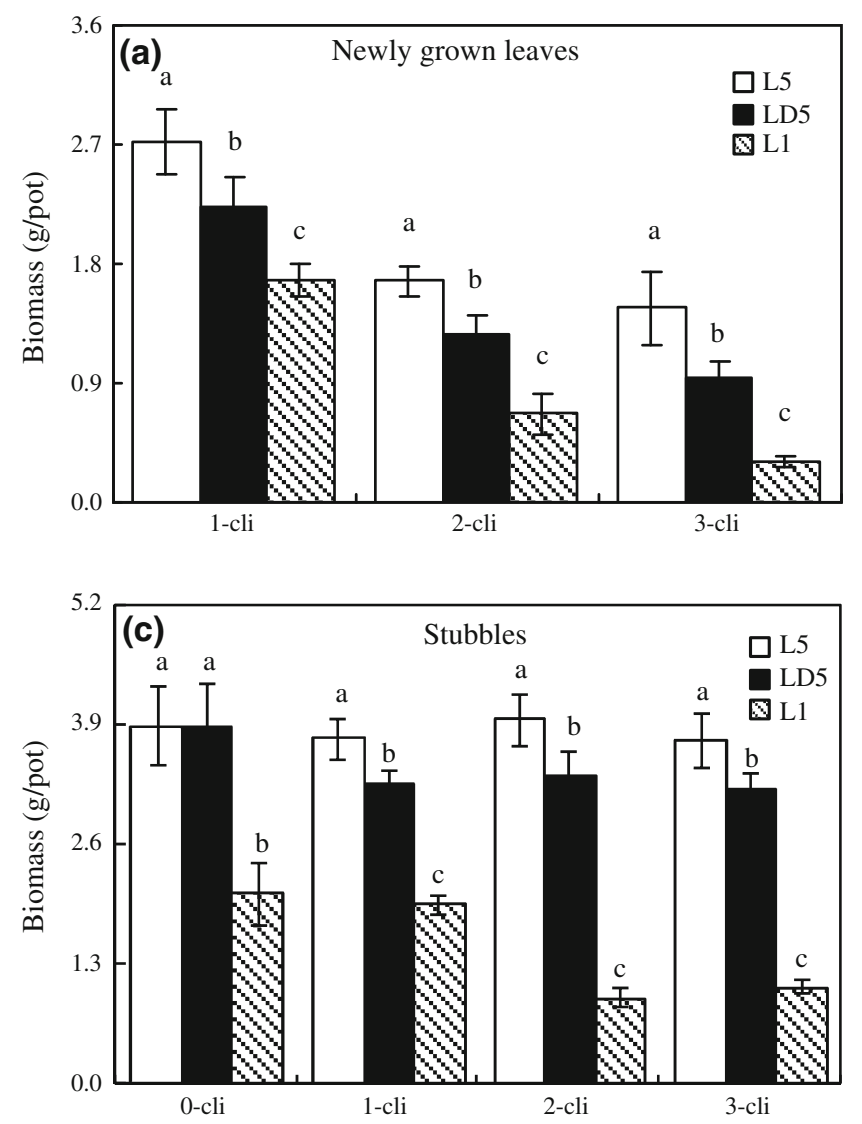

Regrowth index and carbohydrate concentration

Significant differences in RI values (Fig. 7) were found among different treatments 6 days after the first clipping in the order of L1 > L5 > LD5. Six days after the second and third clippings, differences in the values of RI were in the order of L5 > LD $5>$ L1. Soluble carbohydrate concentration in the roots (Fig. 8a) and stubbles (Fig. 8b) decreased by varying degrees 6 days after each clipping compared with their pre-clipping concentrations. The concentrations of soluble carbohydrate in the roots and stubbles were significantly higher in L5 and LD5 than in L1 6 days after each clipping and significantly higher in the roots in L5 than in LD5 6 days after the second and third clippings.

\section{Hormones}

Leaf $\mathrm{Z}+\mathrm{ZR}$ concentration of all treatment groups decreased by varying degrees from 6 days after the first clipping to 6 days after the third clipping (Fig. 9a), and was significantly higher in LD5 and L1 than in L5 6 days after the first clipping, and in L5 than LD5 and L1 6 days after the third clipping. Since Z and ZR are

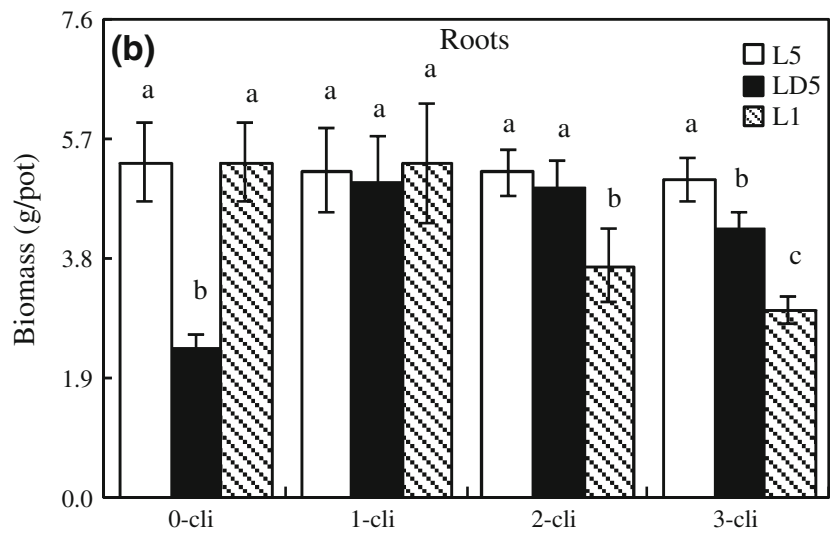

Fig. 6 Newly grown leaf biomass (a), stubble biomass (b), and root biomass (c) in the Exp-3. Values are mean \pm standard error $(n=3)$. Different letters correspond to significant differences at $p \leq 0.05$. "0-cli," "1-cli", "2-cli," and "3-cli" stand for pre-clipping and day 6 after the first, second, and third clippings, respectively 


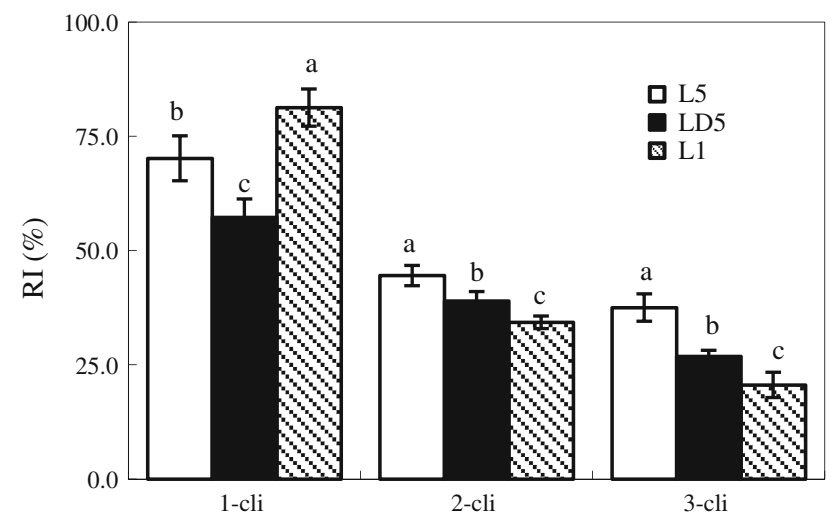

Fig. 7 Relative regrowth index (RI) in different treatments in the Exp-3. Values are mean \pm standard error $(n=3)$. Different letters correspond to significant differences at $p \leq 0.05$. "1-cli," "2-cli," and "3-cli" stand for day 6 after the first, second, and third clippings, respectively

the main forms of cytokinin, these observations indicate that root thinning and low stubble height with root thinning can cause an increase in cytokinin concentration in leaves under single clipping, whereas high stubble height can cause a similar increase under frequent clipping. Root thinning and stubble height had no significant effect on concentrations of ABA, IAA, and GA in leaves (Fig. 9b-d).

The delivery rate of $\mathrm{Z}+\mathrm{ZR}$ from the roots to leaves was significantly higher in LD5 and L1 than in L5 6 days after the first clipping, but was significantly lower in L1 and LD5 than L5 6 days after the third clipping (Fig. 9e). Thus, low stubble height and high stubble height with root thinning increased the delivery rate of $\mathrm{Z}+\mathrm{ZR}$ from the roots to the leaves under single clipping, but reduced delivery rate under frequent clipping conditions. Root thinning and stubble height had no significant effect on ABA delivery rate from the roots to the leaves (Fig. 9f).

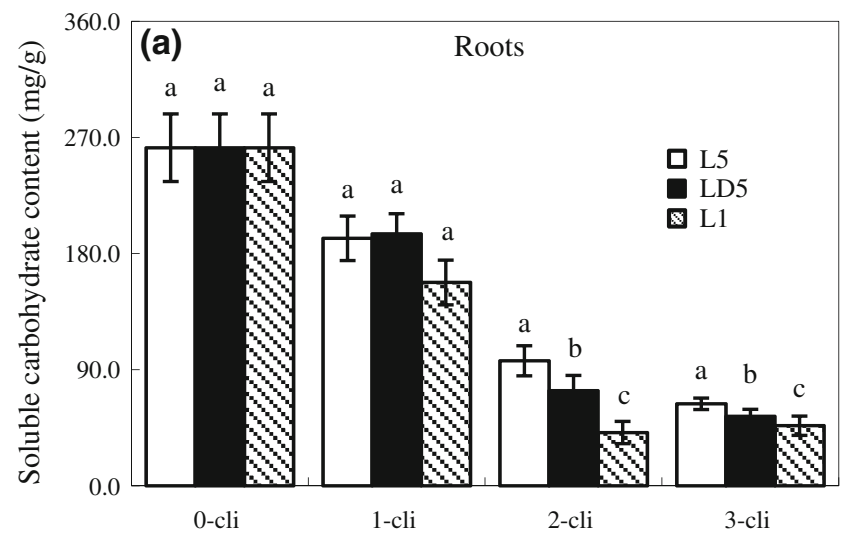

\section{Correlation analysis}

Soluble carbohydrate content of stubbles was not significantly positively correlated with RI 6 days after each clipping (Fig. 10), which indicates that RI is completely independent of stored organic substances in stubbles. Leaf $\mathrm{Z}+\mathrm{ZR}$ concentration showed a significant positive correlation with leaf regrowth biomass (Fig. 11a) and RI (Fig. 12a) 6 days after the second and third clippings. A significant positive correlation was observed between leaf $Z+Z R$ concentration and its delivery rate from the roots to the leaves 6 days after each clipping (Fig. 13a). The concentrations of IAA, GA, and ABA in the leaves showed no significant positive correlation with leaf regrowth biomass (Fig. 11b-d) and RI (Fig. 12b-d). Moreover, ABA concentration in the leaves demonstrated no significant positive correlation with ABA delivery rate (Fig. 13b).

\section{Discussion}

\section{Leaf regrowth in darkness}

Our experiment in darkness (Exp-1) revealed that only stored carbohydrates were involved in leaf regrowth. If carbohydrates from roots were largely involved in leaf regrowth, the soluble carbohydrate concentration of roots in $\mathrm{B} 5$ and $\mathrm{B} 1$, which displayed different leaf regrowth biomass values, would have differed. However, a similar soluble carbohydrate concentration in roots was observed in both treatment groups 6 days after each clipping. Furthermore, B5 had larger roots than BD5, but they had the same regrowth leaf biomass. Thus, our results suggest that only a very small amount of rootderived carbohydrates were involved in leaf regrowth under darkness.

B1 had the shortest stubbles and lowest leaf regrowth biomass among BD5, B5, and B1. Thus, the stored

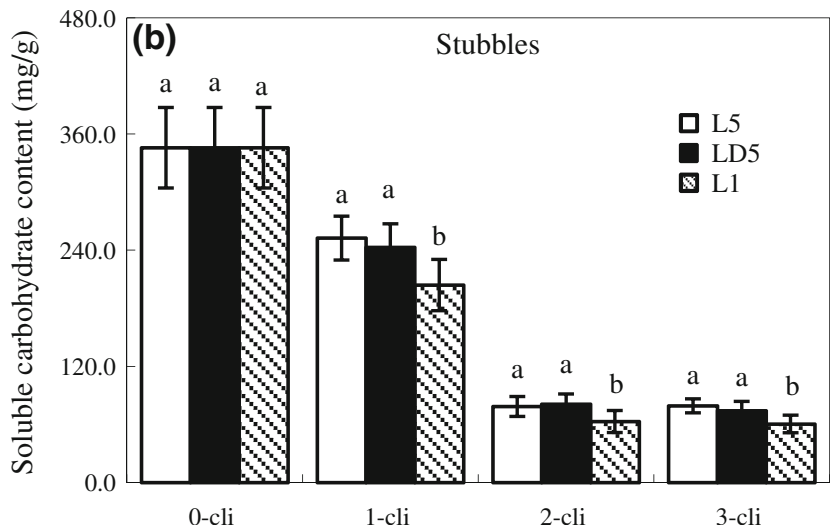

Fig. 8 Soluble carbohydrate concentration in the roots (a) and stubbles (b) in the Exp-3. Values are mean \pm standard error $(n=3)$. Different letters correspond to significant differences at $p \leq 0.05$. "0-cli," "1-cli," "2-cli," and "3-cli" stand for pre-clipping and day 6 after the first, second, and third clippings, respectively 

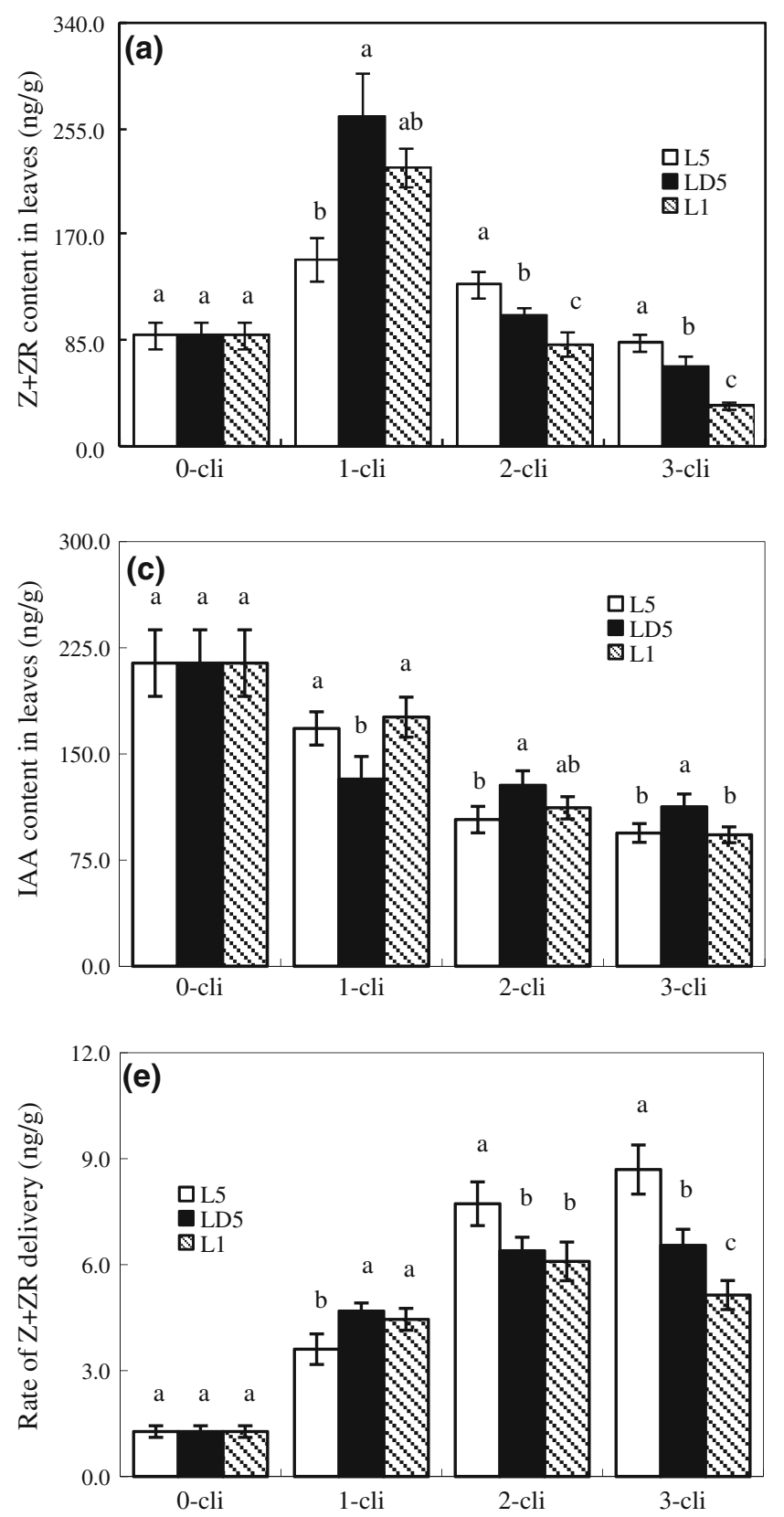

Fig. $9 \mathrm{Z}+\mathrm{ZR}(\mathbf{a}), \mathrm{ABA}(\mathbf{b})$, IAA (c), and GA (d) concentrations in the newly grown leaves, and delivery rates of $Z+Z R$ (e) and ABA (f) from the roots to the leaves in different treatments in the lighting experiment. Values are mean \pm standard error $(n=3)$.

carbohydrate involved in leaf regrowth probably originates predominantly from stubbles under dark conditions. Carbohydrates are the main form of organic matter storage in ryegrass. These results demonstrate that under darkness, stored organic substances in stubbles rather than roots contribute to leaf regrowth. Few studies have found that availability of light increases the use of organic matter stored in roots by leaves. Under light conditions, ryegrass leaves produce large amounts of photosynthates compared with dark conditions. This can further attenuate the potential requirement of leaf regrowth for organic
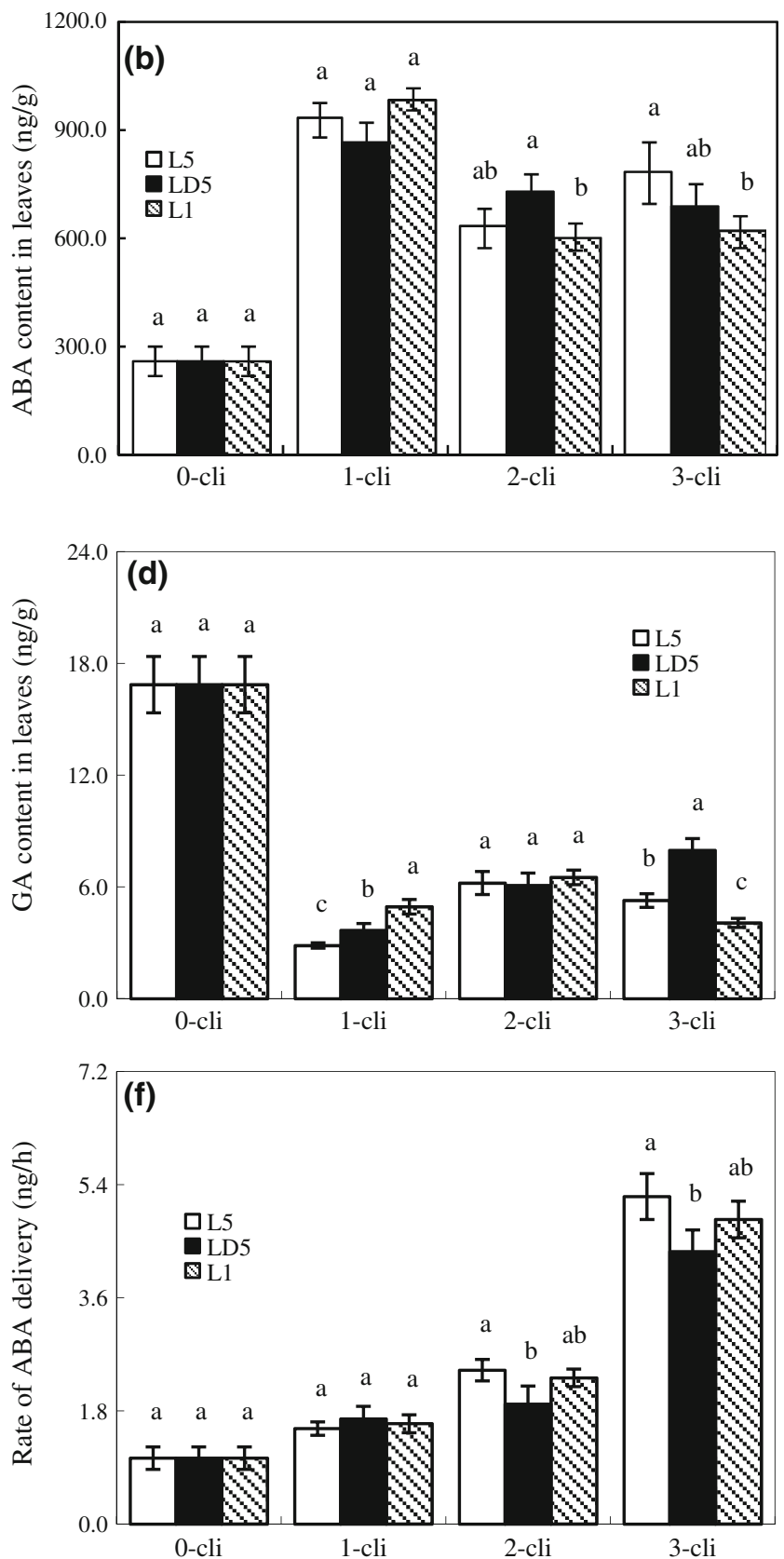

Different letters correspond to significant differences at $p \leq 0.05$. "0-cli," "1-cli," "2-cli," and "3-cli" stand for pre-clipping and day 6 after the first, second, and third clippings, respectively

substances stored in roots. Therefore, under light conditions, organic substances stored in stubbles, compared to those in roots, play key roles in leaf regrowth.

The Similarities in leaf regrowth biomass between S5 and W5, and S1 and W1 6 days after each clipping indicates that photosynthesis in leaf sheaths has very little influence on leaf regrowth. This may be due to the extremely low photosynthesizing capacity of leaf sheaths used in the experiment, which were dry or yellow in color suggesting that they had aged considerably (personal observation, data not shown). 


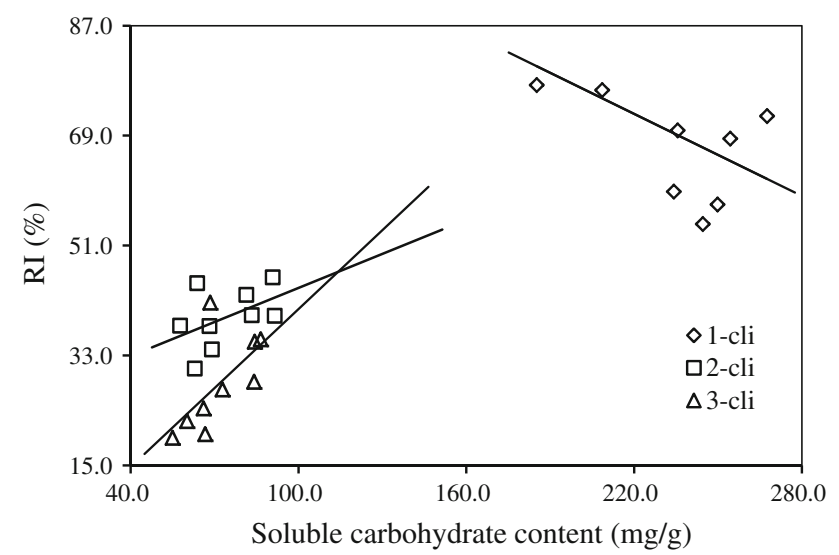

Fig. 10 Relationship between soluble carbohydrate content in stubbles with RI (a) in different treatments of Exp-3. The regression lines for 1-cli, 2-cli, and 3-cli are $y=-0.224 x+121.8\left(r^{2}=\right.$ $0.258, n=9$, non-significant $), y=0.185 x+25.48\left(r^{2}=0.232\right.$, $n=9$, non-significant), and $y=0.430 x-2.485\left(r^{2}=0.394\right.$, $n=9$, non-significant), respectively
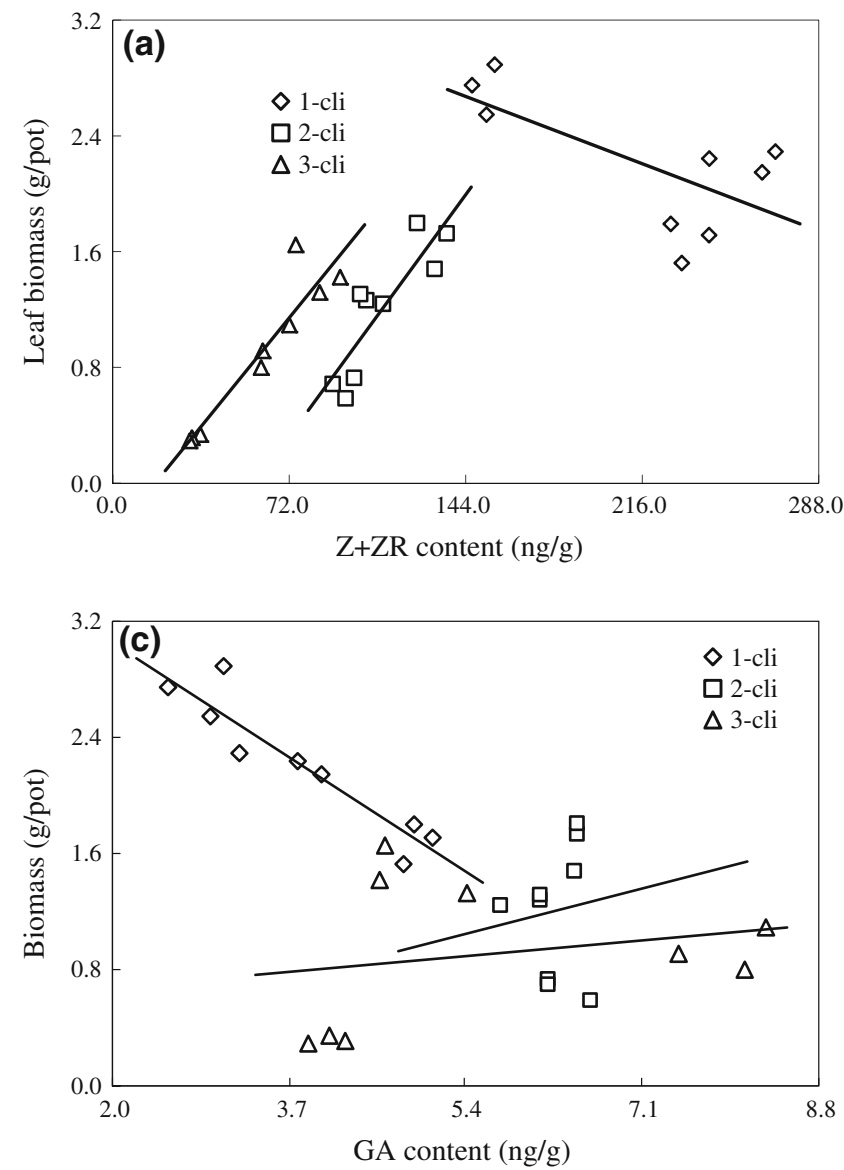

Fig. 11 Relationship between biomass with $\mathrm{Z}+\mathrm{ZR}$ (a), IAA (b), $\mathrm{GA}$ (c), and $\mathrm{ABA}$ (d) concentrations in newly grown leaves in different treatments. In a, the regression lines for 1-cli, 2-cli, and 3 -cli are $y=-0.007 x+3.601\left(r^{2}=0.462, n=9, p<0.05\right)$, $y=0.021 x-0.362 \quad\left(r^{2}=0.881, \quad n=9, \quad p<0.01\right), \quad$ and $y=0.023 x-1.348\left(r^{2}=0.757, n=9, p<0.01\right)$, respectively. In $\mathbf{b}$, the regression lines for 1-cli, 2-cli, and 3-cli are $y=0.008 x+3.439\left(r^{2}=0.136, n=9\right.$, non-significant $), y=$ $0.002 x+1.423 \quad\left(r^{2}=0.003, \quad n=9, \quad\right.$ non-significant $), \quad$ and $y=0.008 x+0.119\left(r^{2}=0.028, n=9\right.$, non-significant $)$, respec-
Leaf regrowth without influence of organic substances in the stubble

Wang et al. (2012, 2013) recently reported that high cytokinin concentration of leaves in ryegrass could increase regrowth. In the present study, higher leaf $\mathrm{Z}+\mathrm{ZR}$ concentration but lower leaf regrowth biomass was observed in L1 when compared with L5 under single clipping. Due to their larger stubbles, L5 plants had larger amount of organic substances stored in their stubbles than L1 plants, and this may have resulted in greater involvement of these organic substances and enhanced leaf regrowth in L5 under single clipping. Under frequent clipping, there was much greater potential involvement of stubble organic substances in leaf regrowth in L5 than L1 because of higher soluble carbohydrate concentrations of stubbles in the former.

Compared with ryegrass whole stubble, each unit weight stubble of different stubble heights has similar
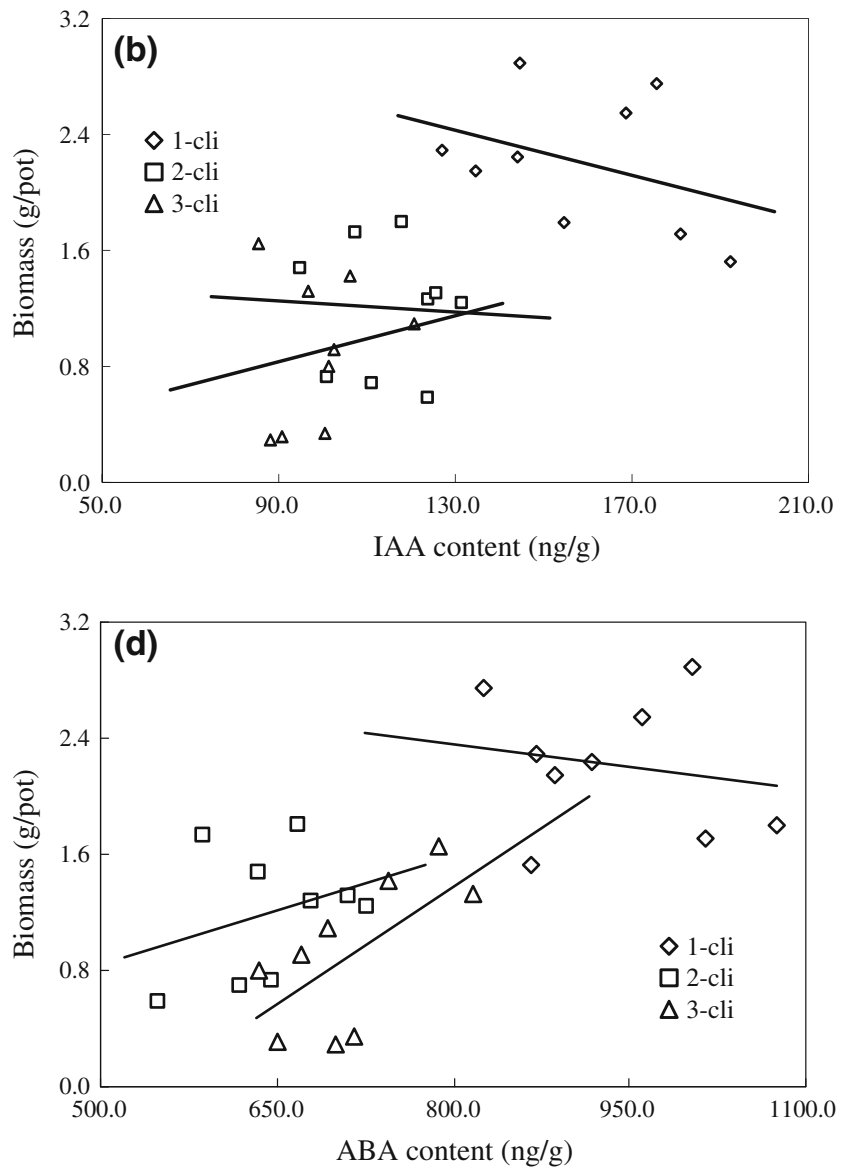

tively. In c, the regression lines for 1-cli, 2-cli, and 3-cli are $y=-0.468 x+3.997 \quad\left(r^{2}=0.873, \quad n=9, \quad p<0.01\right)$, $y=0.184 x+0.047\left(r^{2}=0.013, n=9\right.$, non-significant $)$, and $y=0.063 x+0.550\left(r^{2}=0.050, n=9\right.$, non-significant $)$, respectively. In d, the regression lines for 1-cli, 2-cli, and 3-cli are $y=-0.001 x+3.198 \quad\left(r^{2}=0.034, \quad n=9, \quad\right.$ non-significant $)$, $y=0.0054 x-0.951\left(r^{2}=0.419, n=9\right.$, non-significant $)$, and $y=0.003 x-0.408\left(r^{2}=0.101, n=9\right.$, non-significant $)$, respectively 

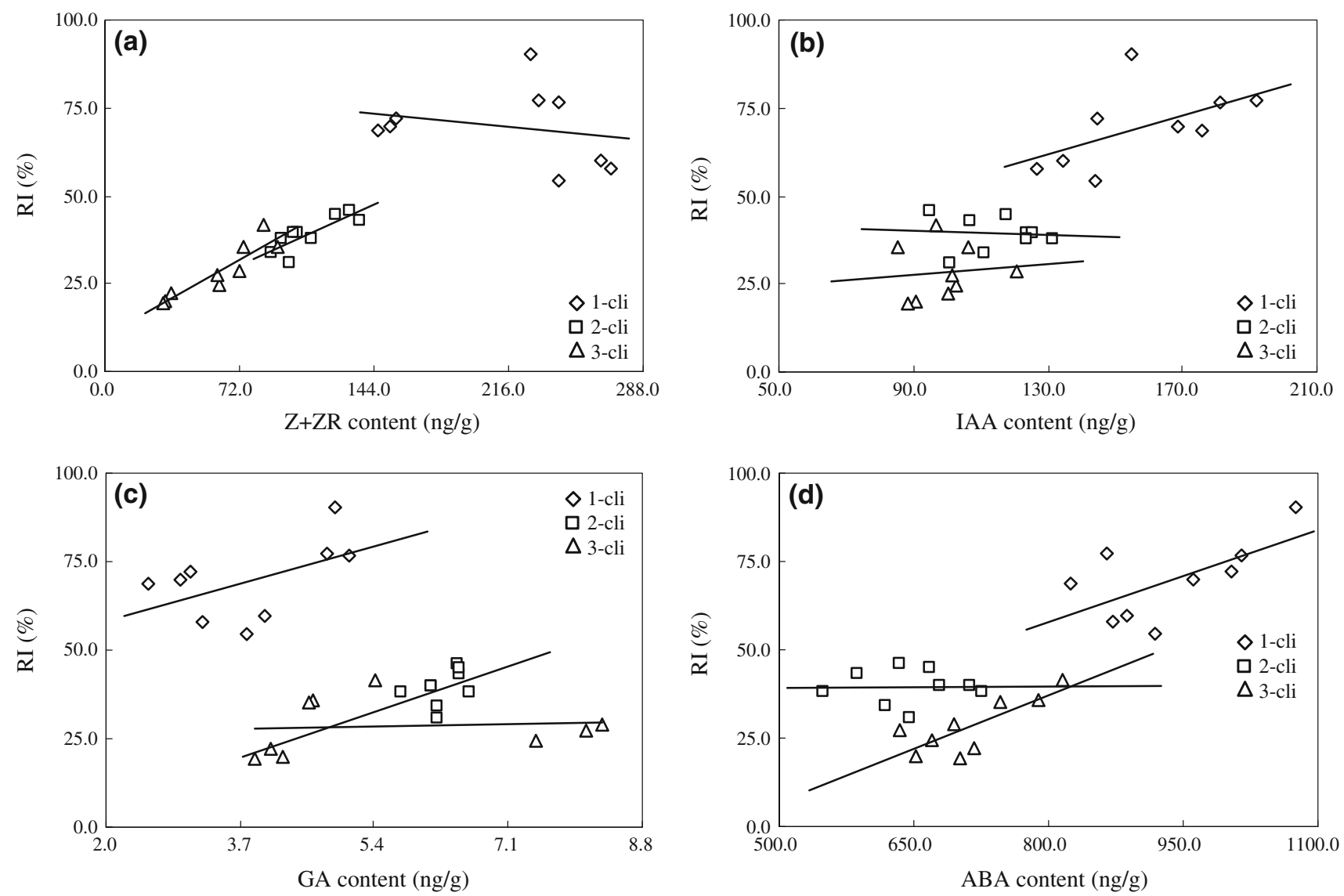

Fig. 12 Relationship between RI with $Z+$ ZR (a), IAA (b), GA (c), and ABA (d) concentrations in newly grown leaves in different treatments of Exp-2. In a, the regression lines for 1-cli, 2-cli, and 3 -cli are $y=-0.055 x+81.418\left(r^{2}=0.059, n=9\right.$, non-significant $), y=0.239 x+13.05\left(r^{2}=0.672, n=9, p<0.01\right)$, and $y=0.306 x+9.802\left(r^{2}=0.823, n=9, p<0.01\right)$, respectively. In $\mathbf{b}$, the regression lines for 1-cli, 2-cli, and 3-cli are $y=0.275 x+26.158\left(r^{2}=0.303, n=9\right.$, non-significant $), y=$ $0.028 x+42.524 \quad\left(r^{2}=0.005, \quad n=9, \quad\right.$ non-significant $), \quad$ and $y=0.0712 x+21.22 \quad\left(r^{2}=0.010, \quad n=9, \quad\right.$ non-significant $)$,
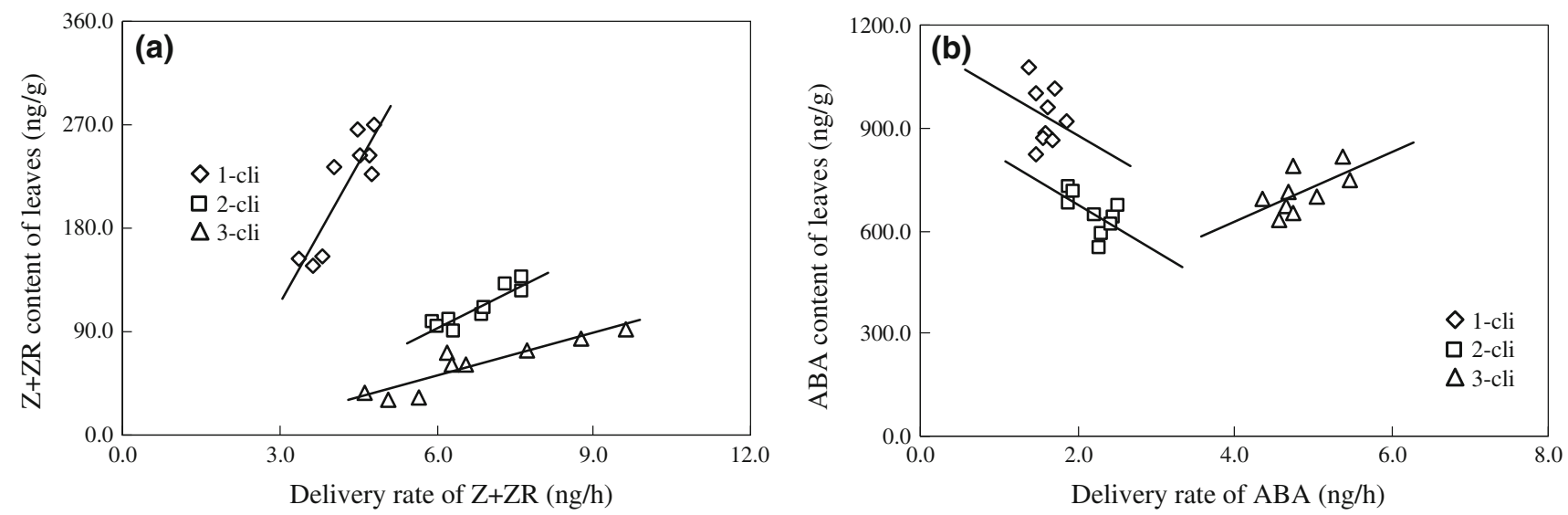

Fig. 13 Relationship between $Z+Z R$ with its delivery rate (a) and ABA with its delivery rate (b). In a, the regression lines for 1-cli, 2-cli, and 3-cli are $y=81.685 x-131.741\left(r^{2}=0.7972\right.$, $n=9, p<0.01), y=22.408 x-41.766\left(r^{2}=0.8109, n=9\right.$, $p<0.01)$, and $y=12.616 x-24.256\left(r^{2}=0.8344, \quad n=9\right.$,

respectively. In c, the regression lines for 1-cli, 2-cli, and 3-cli are $y=6.176 x+46.039 \quad\left(r^{2}=0.270, \quad n=9, \quad\right.$ non-significant $)$, $y=7.583 x-8.286\left(r^{2}=0.178, n=9\right.$, non-significant $)$, and $y=0.382 x+26.186 \quad\left(r^{2}=0.050, \quad n=9, \quad\right.$ non-significant $)$, respectively. In d, the regression lines for 1-cli, 2-cli, and 3-cli are $y=0.086 x-10.336\left(r^{2}=0.399, n=9\right.$, non-significant $)$, $y=0.001 x+38.548\left(r^{2}=0.0002, n=9\right.$, non-significant $)$, and $y=0.099 x-42.81608 \quad\left(r^{2}=0.624, \quad n=9, \quad\right.$ non-significant $)$, respectively

$p<0.01$ ), respectively. In $\mathbf{b}$, the regression lines for 1-cli, 2-cli, and 3-cli are $y=-135.38 x+948.55\left(r^{2}=0.3704, n=9\right.$, nonsignificant), $y=-135.11 x+1151.2\left(r^{2}=0.0613, n=9\right.$, nonsignificant $),$ and $y=100.63 x+223.62\left(r^{2}=0.3762, n=9\right.$, non-significant), respectively 
potential of contributing stored organic substance to leaf regrowth. Calculation of RI in ryegrasses with different stubble heights can minimize the effect of differences in the involvement of stubble-stored organic substances in leaf regrowth. Higher leaf $Z+Z R$ concentration and $\mathrm{RI}$ was observed in L1 compared with L5 plants under single clipping. In the other hand, leaf $\mathrm{Z}+\mathrm{ZR}$ concentration and RI were higher in L5 than in L1, and leaf $\mathrm{Z}+\mathrm{ZR}$ concentration showed a significant positive relationship with RI under frequent clipping. Thus, under minimal influence of stubble-stored organic substances, leaf cytokinin regulates leaf regrowth under single or frequent clipping at different clipping heights.

Root biomass in LD5 increased by $109 \%$, but decreased in L 5 by $2.5 \%$ from pre-clipping to 6 days after the first clipping, indicating that a large amount of photosynthates produced by leaves was transported to the roots in LD5. Therefore, large root growth in LD5 resulted in the lowest RI among treatments of Exp-3 under single clipping. The lowest RI among treatments of Exp-3 resulted in the absence of any significant positive relationship between leaf $\mathrm{Z}+\mathrm{ZR}$ concentration and RI. However, our observation of the highest leaf $\mathrm{Z}+\mathrm{ZR}$ concentration in LD5 under single clipping among treatment groups of Exp-3 showed that, large root growth in LD5 was indirectly caused by leaf cytokinins.

Although no noticeable effects of GA or IAA were found on regrowth leaf biomass or RI, they were likely valuable for the regrowth of ryegrass since expression level and functions of most phytohormones are closely related to each other (Goda et al. 2008). In addition, plant growth is under comprehensive regulation of various hormones including auxin, gibberellin, and cytokinin. Leaf regrowth of ryegrass mainly involves increase in cell numbers and cell volume enlargement, and subsequent accumulation of photosynthetic products. Gibberellin promotes cell elongation, and auxin increases cell elongation and expansion by promoting cell wall plasticity. Cytokinin is involved in plant cell division and horizontal elongation, and plays a dominant role in increase of cell numbers and volume enlargement. In addition, cytokinin helps to increase nitrogen availability in leaves by inducing the upward transport of nitrogen from plant roots to leaves (Tamaki and Mercier 2007; Sakakibara et al. 2006). The photosynthetic activity of plant leaves is increased by the accumulation of nitrogen (Kobayashi et al. 2010, 2012). Thus, cytokinin can also increase the photosynthetic capability of leaves and it plays a dominant role in leaf regrowth by inducing organic substance accumulation.

Cytokinin from plant roots is transported in xylem sap to the stems and leaves aboveground and accumulates in leaves (Dodd 2005; Zaicovski et al. 2008). Ghanem et al. (2011) reported that gene expression of root-localized transgenic isopentenyl transferase, a key enzyme in cytokinin biosynthesis, can increase the concentrations of bioactive cytokinins in the root, xylem sap, and leaves of Solanum lycopersicum L. Our obser- vation of direct connection between the delivery rate of $Z+Z R$ from the roots to the leaves and the leaf $Z+Z R$ concentration 6 days after each clipping in Exp-3 shows that roots are able to regulate leaf $Z+Z R$ concentration under single or frequent clipping.

Xylem-cytokinin is used as an index of cytokinin delivery from the roots to the shoots in pea plants (Dodd et al. 2004). However, sap exuding from de-topped root systems travels at a much lower flow rate than transpirational flow rate. Therefore, the product of transpiration rate and xylem cytokinin concentration is used to express photoperiod cytokinin delivery rate, which is an indicator of the effect of xylem-supplied cytokinins on leaf expansion. In the present study, clipping greatly reduced the leaf area of ryegrass, which is not conducive for leaf transpiration. Leaf transpiration is also poor in the absence of light at night, so a very small amount of cytokinin is probably transported from roots to leaves through xylem sap by this process at night. However, ryegrass grows rapidly after clipping at night (personal observation, data not shown). Therefore, in our study, transpiration may not have influenced cytokinins delivery from the roots to shoots.

Considering the shoot-to-root ratio, clipping in L1 resulted in relatively large roots after the first clipping because of low stubble height. In plants, larger roots can usually support larger stems and leaves aboveground. Hessini et al. (2009) found that the shoot-to-root fresh weight ratio increased after 90 days of sowing in Spartina alterniflora, suggesting that shoot weight increases with increasing root weight. Increased root weight and simultaneous aboveground biomass was observed under irrigation in spring wheat planted in rain-fed farming systems (Song et al., 2009). In this study, the large roots in L1 affected regrowth under single clipping, thus inducing cytokinin in roots in L1 to adjust leaf regrowth. This phenomenon may explain the higher delivery rate of $\mathrm{Z}+\mathrm{ZR}$ from the roots to the leaves in $\mathrm{L} 1$ compared with L5 under single clipping. Cytokinin synthesis mainly occurs in the new tissue of roots. Root thinning stimulated the growth of newborn LD5 roots under single clipping, as indicated by the large increase in root biomass from pre-clipping to 6 days after the first clipping. The newborn roots included primary and lateral roots (personal observation, data not shown). Therefore, a higher delivery rate of $Z+Z R$ from the roots to the leaves was observed in LD5 than L1 and L5 6 days after the first clipping.

The low soluble carbohydrate content of stubbles and low leaf regrowth capacity both reduce the amount of carbohydrate imported into roots in L1 under frequent clipping. However, root metabolism utilizes large amount of carbohydrates. Therefore, low soluble carbohydrate content and biomass of roots was observed in L1 under frequent clipping. This explains the lower delivery rate of $Z+Z R$ from the roots to the leaves observed in L1 compared with LD5 and L5 under frequent clipping. Since hormone synthesis and root secretion require high amounts of energy and materials. 
Root thinning also resulted in lower biomass and root carbohydrate concentration in LD5 than L5 6 days after the second and third clippings. This may be the main reason for the observed low delivery rate of $\mathrm{Z}+\mathrm{ZR}$ from the roots to the leaves under frequent clipping.

\section{Conclusions}

In this study, we found that stored organic substances in stubbles rather than roots are key for leaf regrowth. Under single clipping, low stubble height and root clipping reduced leaf biomass and increased RI, and $\mathrm{Z}+\mathrm{ZR}$ concentration of leaves. However, at high stubble height under frequent clipping, leaf $Z+Z R$ concentration, leaf biomass, and RI were all higher than those at low stubble height. The delivery rate of $Z+Z R$ from the roots to the leaves exhibited significant positive correlation with $Z+Z R$ concentration in leaves under single or frequent clipping. Thus, our results indicate that root-derived cytokinin concentration in leaves, which is affected by clipping height, has direct effect on ryegrass regrowth.

Acknowledgments This work was supported by the National Natural Science Foundation of China program (U1304326), the Scientific Research Program of Henan Provincial Education Department in China (2011A180012), the innovation capability cultivation foundation in natural science of Henan university of Science and technology (2012ZCX007), and the special Postdoctoral Science Foundation of China (201003183) in 2010.

Open Access This article is distributed under the terms of the Creative Commons Attribution License which permits any use, distribution, and reproduction in any medium, provided the original author(s) and the source are credited.

\section{References}

Andreasen C, Hansen CH, Møller C, Kjær-Pedersen N (2002) Regrowth of weed species after clipping. Weed Technol $16: 873-879$

Bacaicoa E, Mora V, Zamarreño AM, Fuentes M, Casanova E, García-Mina JM (2011) Auxin: a major player in the shoot-toroot regulation of root $\mathrm{Fe}$-stress physiological responses to $\mathrm{Fe}$ deficiency in cucumber plants. Plant Physiol Biochem 49:545-556

Bano A (2010) Root-to-shoot signal transduction in rice under salt stress. Pak J Bot 42:329-339

Coelho M, Colebrook EH, Lloyd DPA, Webster CP, Mooney SJ, Phillips AL, Hedden P, Whalley WR (2013) The involvement of gibberellin signalling in the effect of soil resistance to root penetration on leaf elongation and tiller number in wheat. Plant Soil 371:81-94

Conn JS, Seefeldt SS (2009) Invasive white sweetclover (Melilotus officinalis) control with herbicides, clipping, and flaming. Invasive Plant Sci Manage 2:270-277

Dodd IC (2005) Root-to-shoot signalling: assessing the roles of 'up' in the up and down world of long-distance signalling in planta. Plant Soil 274:251-270

Dodd IC, Ngo C, Turnbull CGN, Beveridge CA (2004) Effects of nitrogen supply on xylem cytokinin delivery, transpiration and leaf expansion of pea genotypes differing in xylem-cytokinin concentration. Funct Plant Biol 31:903-911
Gan YM, Schnyder H, Vianden H, Schaeufele R (1999) Variation of carbohydrate and nitrogen contents in regrowth of perennial rye-grass after clipping. Acta Prataculturae Sin 8:65-70 (in Chinese with English abstract)

Gastal F, Dawson LA, Thornton B (2010) Responses of plant traits of four grasses from contrasting habitats to clipping and $\mathrm{N}$ supply. Nutr Cycl Agroecosyst 88:245-258

Ghanem ME, Albacete A, Smigocki AC, Frèbort I, Pospíšilová H, Martínez-Andújar C, Acosta M, Sánchez-Bravo J, Lutts S, Dodd IC, Pérez-Alfocea F (2011) Root-synthesized cytokinins improve shoot growth and fruit yield in salinized tomato (Solanum lycopersicum L.) plants. J Exp Bot 62:125-140

Goda H, Sasaki E, Akiyama K, Maruyama-Nakashita A, Nakabayashi K, Li WQ, Ogawa M, Yamauchi Y, Preston J, Aoki K, Kiba T, Takasuto S, Fujioka S, Asam T, Nakano T, Kato H, Mizuno T, Sakakibara H, Yamaguchi S, Nambara E, Kamiya Y, Takahashi H, Hirai MY, Sakurai T, Shinozaki K, Saito K, Yoshida S, Shimada Y (2008) The AtGenExpress hormone and chemical treatment data set: experimental design, data evaluation, model data analysis and data access. Plant $\mathbf{J}$ 55:526-542

Guevara JC, Estevez OR, Stasi CR, Gonnet JM (2002) Perennial grass response to 10 -year cattle grazing in the Mendoza plain, mid-west Argentina. J Arid Environ 52:339-348

He Z (1993) Guidance to experiment on chemical control in crop plants. Beijing Agricultural University Publishers, Beijing, pp 60-68

Hessini K, Martínez JP, Gandour M, Albouchi A, Soltani A, Abdelly C (2009) Effect of water stress on growth, osmotic adjustment, cell wall elasticity and water-use efficiency in Spartina alterniflora. Environ Exp Bot 67:312-319

Hoshino A, Tamura K, Fujimaki H, Asano M, Ose K, Higashi T (2009) Effects of crop abandonment and grazing exclusion on available soil water and other soil properties in a semi-arid Mongolian grassland. Soil Tillage Res 105:228-235

Kobayashi H, Inoue S, Gyokusen K (2010) Spatial and temporal variations in the photosynthesis-nitrogen relationship in a Japanese cedar (Cryptomeria japonica D. Don) canopy. Photosynthetica 48:249-256

Kobayashi H, Inoue S, Gyokusen K (2012) Photosynthesis-nitrogen relationship in a Hinoki cypress (Chamaecyparis obtusa) canopy: a comparison with Japanese cedar (Cryptomeria japonica). Photosynthetica 50:317-320

Lee JM, Donaghy DJ, Sathish P, Roche JR (2009) Interaction between water-soluble carbohydrate reserves and clipping severity on the regrowth of perennial ryegrass (Lolium perenne L.)-dominant swards. Grass Forage Sci 64:266-275

Regmi PR, Devkota NR (2009) Effects of nitrogen fertilization and clipping height on the forage yield and feeding value of Eleusine indica in the dry season in Nepal. Weed Biol Manage 9:106-111

Sakakibara H, Takei K, Hirose N (2006) Interactions between nitrogen and cytokinin in the regulation of metabolism and development. Trends Plant Sci 11:440-448

Schiborra A, Gierus M, Wan HW, Bai YF (2009) Short-term responses of a Stipa grandis/Leymus chinensis community to frequent clipping in the semi-arid grasslands of Inner Mongolia, China. Agric Ecosyst Environ 132:82-90

Shi K, Hu WH, Dong DK, Zhou YH, Yu JQ (2007) Low $\mathrm{O}_{2}$ supply is involved in the poor growth in root-restricted plants of tomato (Lycopersicon esculentum Mill.). Environ Exp Bot 61:181-189

Song L, Li FM, Fan XW, Xiong YC, Wang WQ, Wu XB, Turner NC (2009) Soil water availability and plant competition affect the yield of spring wheat. Eur J Agron 31:51-60

Tamaki V, Mercier H (2007) Cytokinins and auxin communicate nitrogen availability as long-distance signal molecules in pineapple (Ananascomosus). J Plant Physiol 164:1543-1547

Teng NJ, Wang J, Chen T, Wu XQ, Wang YH, Lin JX (2006) Elevated $\mathrm{CO}_{2}$ induces physiological, biochemical and structural changes in leaves of Arabidopsis thaliana. New Phytol 172:92-103 
Turner LR, Donaghv DJ, Lane PA, Rawnsley RP (2007) Distribution of water-soluble carbohydrate reserves in the stubble of prairie grass and orchardgrass plants. Agron J 99:591-594

Veselova SV, Farhutdinov RG, Veselov SY, Kudoyarova GR, Veselov DS, Hartung W (2005) The effect of root cooling on hormone content, leaf conductance and root hydraulic conductivity of durum wheat seedlings (Triticum durum L.). J Plant Physiol 162:21-26

Vysotskaya LB, Korobova AV, Kudoyarova GR (2008) Abscisic acid accumulation in the roots of nutrient-limited plants: its impact on the differential growth of roots and shoots. J Plant Physiol 165:1274-1279

Wang XL, Liu D, Li ZQ (2012) Effects of the coordination mechanism between roots and leaves induced by root-breaking and exogenous cytokinin spraying on the grazing tolerance of ryegrass. J Plant Res 125:407-416

Wang XL, Wang J, Li ZQ (2013) Correlation of continuous ryegrass regrowth with cytokinin induced by root nitrate absorption. J Plant Res 126:685-697

Weiler EW, Jordan PS, Conrad W (1981) Levels of indole-3-acetic acid in intact and decapitated coleoptiles as determined by a specific and highly sensitive solid-phase enzyme immunoassay. Planta 153:561-571

Wu S, Chen W, Zhou X (1988) Enzyme linked immunosorbent assay for endogenous plant hormones. Plant Physiol Commun 5:53-57 (in Chinese with English abstract)

Yang JC, Zhang JH, Wang ZQ, Zhu QS, Wang W (2001) Hormonal changes in the grains of rice subjected to water stress during grain filling. Plant Physiol 127:315-323
Yang JC, Zhang JH, Wang ZQ, Zhu QS, Liu LJ (2004) Activities of fructan- and sucrose-metabolizing enzymes in wheat stems subjected to water stress during grain filling. Planta 220:331-343

Zaicovski CB, Zimmerman T, Nora L, Nora FR, Silva JA, Rombaldi CV (2008) Water stress increases cytokinin biosynthesis and delays postharvest yellowing of broccoli florets. Postharvest Biol Technol 49:436-439

Zhang J, He Z, Wu Y (1991) Establishment of an indirect enzymelinked immunosorbent assay for zeatin and zeatin riboside. J Beijing Agric Univ Suppl 17:145-151 (in Chinese with English abstract)

Zhang H, Tan GL, Yang LN, Yang JC, Zhang JH, Zhao BH (2009) Hormones in the grains and roots in relation to postanthesis development of inferior and superior spikelets in japonica/indica hybrid rice. Plant Physiol Biochem 47:195-204

Zhang XX, Li CJ, Nan ZB (2011) Effects of clipping frequency and height on alkaloid production in endophyte-infected drunken horse grass (Achnatherum inebrians). Sci China Life Sci 54:567-571

Zhao W, Chen SP, Lin GH (2008) Compensatory growth responses to clipping in Leymus chinensis (Poaceae) under nutrient addition and water deficiency conditions. Plant Ecol 139:133-144

Zhu SF, Gao F, Cao XS, Chen M, Ye GY, Wei CH, Li Y (2005) The rice dwarf virus $\mathrm{P} 2$ protein interacts with ent-kaurene oxidases in vivo, leading to reduced biosynthesis of gibberellins and rice dwarf symptoms. Plant Physiol 139:1935-1945

Zou Q (1995) Guide to physiological and biochemical experiments. China Agriculture Publishing House, Beijing, pp 53-69 